\title{
Prophylactic ip injection of bupivacaine and/or morphine does not improve postoperative analgesia after laparoscopic gynecologic surgery
}

\author{
[L'injection intrapéritonéale préventive de bupivacaïne et/ou de morphine n'améliore \\ pas l'analgésie postopératoire après une intervention gynécologique laparoscopique]
}

Hawa Keita MD PhD, ${ }^{*}$ Jean Louis Benifla MD, $†$ Violaine Le Bouar, $¥$ Raphaël Porcher MD PhD,,$\$$ Bogena Wachowska MD, ${ }^{*}$ Karima Bedairia MD, ${ }^{*}$ Jean Mantz MD PhD, ${ }^{*}$ Jean Marie Desmonts MD*

\begin{abstract}
Purpose: To determine the effectiveness of ip bupivacaine and/or morphine for postoperative analgesia after laparoscopic surgery. A controversy exists on the effectiveness and clinical value of ip injection of local anesthetics for postoperative analgesia. A possible peripheral analgesic effect of morphine after ip injection remains debated as well.
\end{abstract}

Methods: We conducted a randomized, double-blinded, study to compare the efficacy of prophylactic ip administration of $0.9 \%$ saline $(n=16), 0.5 \%$ bupivacaine $(100 \mathrm{mg}, n=15)$, morphine (3 $\mathrm{mg}, n=16)$ and a mixture with $0.5 \%$ bupivacaine $(100 \mathrm{mg})$ and morphine (3 mg, $n=18$ ) to reduce both postoperative pain scores and analgesic requirements after gynecologic laparoscopic surgery. A multimodal analgesia regimen (acetaminophen, nonsteroidal antiinflammatory drugs and morphine) was used for postoperative analgesia.

Results: No difference was observed in postoperative pain scores (visual analogue scale at rest and on coughing), or analgesic requirements during the first 24 postoperative hours between the four groups. There was also no significant intergroup difference in sedation scores and incidence of nausea and vomiting.

Conclusion: When multimodal postoperative analgesia is used, prophylactic ip administration of $100 \mathrm{mg}$ bupivacaine and/or $3 \mathrm{mg}$ morphine does not significantly improve postoperative analgesia in patients undergoing laparoscopic gynecologic surgery.

\begin{abstract}
Objectif : Déterminer l'efficacité de l'administration intrapéritonéale ip de bupivacaïne et/ou de morphine pour l'analgésie postopératoire en chirurgie laparoscopique. L'efficacité et la valeur clinique de l'injection ip d'anesthésiques locaux pour l'analgésie postopératoire, de même que l'effet analgésique périphérique possible de la morphine après l'injection ip, demeurent discutables.
\end{abstract}

Méthode : L'étude, randomisée et à double insu, voulait comparer l'efficacité de l'administration ip prophylactique de solution saline à $0,9 \%(n=16)$, de $100 \mathrm{mg}$ de bupivacaïne à $0,5 \%(n=15)$, de $3 \mathrm{mg}$ de morphine $(n=16)$ et d'un mélange de $100 \mathrm{mg}$ de bupivacaïne à $0,5 \%$ et de $3 \mathrm{mg}$ de morphine $(n=18)$ pour réduire la douleur postopératoire et les besoins analgésiques à la suite d'une intervention gynécologique laparoscopique. Une analgésie multimodale (acétaminophène, anti-inflammatoires non stéroïdiens et morphine) a été utilisée pour l'analgésie postopératoire.

Résultats : Aucune différence intergroupe n'a été observée quant aux scores de douleur postopératoire (échelle visuelle analogique au repos et pendant la toux) ou aux besoins analgésiques pendant les 24 premières heures postopératoires. Les scores de sédation et l'incidence de nausées et de vomissements n'ont pas présenté non plus de différence intergroupe.

Conclusion : Quand on utilise une analgésie postopératoire multimodale, l'administration prophylactique ip de $100 \mathrm{mg}$ de bupivacaïne et/ou de 3 mg de morphine n'améliore pas significativement l'analgésie postopératoire en chirurgie gynécologique laparoscopique.

From the Departments of Anesthesiology, ${ }^{*}$ Gynecology, $†$ and Pharmacy, $\ddagger$ Hospital Bichat; and the Department of Biostatistics, $\$$ Hospital Saint-Louis, Paris, France.

Address correspondence to: Dr. Hawa Keita, Department of Anesthesiology and Intensive Care, Hospital Bichat, 46 rue Henri Huchard, 75018 Paris, France. Phone: 33-1-40-25-81-16; Fax: 33-1-42-28-99-96; E-mail: hawakeita@club-internet.fr

Supported by grants from Assistance Publique-Hôpitaux de Paris, France. Presented, in part, at the annual meeting of the American

Society of Anesthesiologists, October 14-18, 2000, San Francisco, CA, USA.

Accepted for publication October 22, 2002.

Revision accepted January 16, 2003. 
$\mathrm{L}$ APAROSCOPIC surgery, compared to open procedures, is a minimally invasive technique associated with reduced postoperative pain. ${ }^{1-3}$ Nonetheless, pain after laparoscopy may be moderate or even severe for some patients. ${ }^{4}$ Intraperitoneal injection of local anesthetics has been proposed to minimize postoperative pain after laparoscopic surgery. However, a controversy exists over the effectiveness and clinical value of this procedure for pain control after laparoscopic cholecystectomy. ${ }^{5}$ Several reports are available on the efficacy of ip local anesthetic administration for analgesia after laparoscopic gynecologic surgery. ${ }^{6-8}$ All these studies report an attenuation of postoperative pain when local anesthetics (bupivacaine or ropivacaine) were administrated at the end of surgery. One study evaluated the prophylactic treatment of postoperative pain with ip injection of local anesthetics before surgery in daycase laparoscopic gynecologic surgery. ${ }^{9}$ In this study, Narchi et al. reported lower postoperative pain scores and incidence of shoulder pain with local anesthetics compared to placebo.

Intraperitoneal injection of opioids for postoperative analgesia has been evaluated as an alternative approach. It has been suggested that peripheral antinociceptive effects of opioid agonists could be elicited by activation of opioid receptors localized on peripheral sensory nerves. ${ }^{10}$ However, SchulteSteinberg et al. failed to demonstrate any analgesic effect of ip morphine $(0.25 \mathrm{mg})$ after laparoscopic cholecystectomy. ${ }^{11}$ This result was explained, in part, by a very small amount of drug delivered to the surgical site. On the basis of these data, we conducted a study where we hypothesized that prophylactic ip administration of higher doses of morphine $(3 \mathrm{mg})$ and/or $100 \mathrm{mg}$ bupivacaine before the beginning of laparoscopic gynecologic surgery provides more effective postoperative analgesia compared to placebo when associated to multimodal analgesia.

\section{Methods}

Patient selection and protocol

The study was approved by our Institutional Ethic Committee for Research on Human Subjects. Seventy-two patients gave their written, informed consent. All patients aged 18-40 yr, ASA I or II, scheduled for laparoscopic gynecologic surgery were included in this prospective, randomized, placebocontrolled and double-blinded study. Operations were conducted to treat tubal infertility, chronic salpingitis, suspected endometriosis or ovarian disease. Patients who presented for emergency operations, those with a history of malignancy, or those presenting contraindi- cations to acetaminophen (allergy, liver disease), to nonsteroidal anti-inflammatory drugs (esophagogastroduodenal disease, renal insufficiency, abnormal coagulation), or with confirmed local anesthetic allergy, were not included. All patients received instructions on how to use the visual analogue scale [VAS; grading from $0 \mathrm{~mm}$ (no pain) to $100 \mathrm{~mm}$ (worst imaginable pain)] for pain assessment before surgery.

The same surgical team carried out all operations.

Patients received oral premedication with $1 \mathrm{mg} \cdot \mathrm{kg}^{-1}$ hydroxyzine one hour before surgery. General anesthesia was induced and maintained with propofol in target-controlled infusion mode using a Graseby 3400 syringe pump (Graseby Medical, Watford, UK) and alfentanil infusion at a plasma target concentration of $60 \mathrm{ng} \cdot \mathrm{mL}^{-1}$ (Stanpump, pharmacokinetic model reported by Maitre et al.). ${ }^{12}$ Propofol target concentration was adjusted to maintain mean arterial pressure and/or heart rate within $-30 \%$ and $-10 \%$ of the baseline values respectively. Tracheal intubation was facilitated with vecuronium bromide $\left(0.1 \mathrm{mg} \cdot \mathrm{kg}^{-1}\right)$. Additional doses of vecuronium were administrated for abdominal muscle relaxation and to facilitate the surgical procedure. Ventilation (tidal volume, $8-10 \mathrm{~mL} \cdot \mathrm{kg}^{-1}$ ) was adjusted to maintain end-tidal carbon dioxide between 35 and $40 \mathrm{mmHg}$ with $50 \%$ nitrous oxide in oxygen. During surgery, all patients received an $i v$ infusion of lactated Ringer's solution at a rate of 5-7 $\mathrm{mL} \cdot \mathrm{kg}^{-1} \cdot \mathrm{hr}^{-1}$ intraoperatively and $\mathrm{l}-2$ $\mathrm{mL} \cdot \mathrm{kg}^{-1} \cdot \mathrm{hr}^{-1}$ during the subsequent 24 -hr period.

The test solutions were drawn into four coded syringes by the pharmacist: a $20-\mathrm{mL}$ syringe containing $20 \mathrm{~mL}$ of $0.5 \%$ bupivacaine with epinephrine l:200 000 or $20 \mathrm{~mL} 0.9 \%$ saline and a $5-\mathrm{mL}$ syringe containing $3 \mathrm{~mL}$ of either morphine in $0.9 \%$ saline or $0.9 \%$ saline. The anesthesiologist, the surgeon and postanesthesia care unit (PACU) and ward nurses were unaware of patient allocation. Patients were assigned to four different groups by use of a random number table (18 patients per group). Group B: 20 $\mathrm{mL}$ of $0.5 \%$ bupivacaine with epinephrine 1:200 000 and $3 \mathrm{~mL} 0.9 \%$ saline; Group M: $3 \mathrm{mg}$ morphine and $20 \mathrm{~mL} 0.9 \%$ saline; Group B + M: $20 \mathrm{~mL}$ of $0.5 \%$ bupivacaine with epinephrine $1: 200000$ and $3 \mathrm{mg}$ morphine; Group S: $23 \mathrm{~mL}$ 0.9\% saline. Treatment solutions $(23 \mathrm{~mL}$ for each patient $)$ were administered immediately after creation of a pneumoperitoneum, before the beginning of surgery. The surgeon sprayed $12 \mathrm{~mL}$ in the right subdiaphragmatic area and $11 \mathrm{~mL}$ into the pelvic cavity under visual control.

\section{Postoperative management}

After surgery, patients were transferred to the PACU and asked every five minutes to evaluate their pain on 
TABLE I Demographic characteristics and surgical variables of patients receiving ip bupivacaine (Group B), morphine (Group M), bupivacaine + morphine (Group B + M) or saline (Group S)

\begin{tabular}{lllll}
\hline & $\begin{array}{l}\text { Group } B \\
(n=15)\end{array}$ & $\begin{array}{l}\text { Group } M \\
(n=16)\end{array}$ & $\begin{array}{l}\text { Group B+M } \\
(n=18)\end{array}$ & $\begin{array}{l}\text { Group } S \\
(n=16)\end{array}$ \\
\hline Age $(\mathrm{yr})$ & $33(27.5-35)$ & $32(29-34)$ & $29(26-37)$ & $32.5(29-36)$ \\
Weight $(\mathrm{kg})$ & $58(53.5-68.5)$ & $64(53-73)$ & $59(51-80)$ & $59(54-66)$ \\
Height $(\mathrm{cm})$ & $160.5(157.5-162.5)$ & $168(165-170)$ & $167(160-169)$ & $161(158-171)$ \\
ASA (I/II) & $15 / 0$ & $15 / 1$ & $17 / 1$ & $16 / 0$ \\
Duration of surgery (min) & $66.5(35.5-102.5)$ & $55(40-100)$ & $45(35-110)$ & $51.5(35-83)$ \\
Intraoperative propofol $(\mathrm{mg})$ & $985.5(676-1493.5)$ & $1000(685-1293)$ & $845(580-1330)$ & $953(652-1280)$ \\
Intraoperative alfentanil $(\mathrm{mg})$ & $2540(2060-4060)$ & $2800(2400-3400)$ & $2400(1800-2400)$ & $2610(2200-3000)$ \\
\hline
\end{tabular}

Values are medians (25th-75th). No statistically significant differences between groups.

TABLE II Pain scores, shoulder pain, time to first analgesic request and consumption of analgesics

\begin{tabular}{lllll}
\hline & $\begin{array}{l}\text { Group } B \\
(n=15)\end{array}$ & $\begin{array}{l}\text { Group } M \\
(n=16)\end{array}$ & $\begin{array}{l}\text { Group } B+M \\
(n=18)\end{array}$ & $\begin{array}{l}\text { Group } S \\
(n=16)\end{array}$ \\
\hline$V A S-R$ & & & & \\
$0 \mathrm{hr}$ & $40(0-60)$ & $40(10-80)$ & $30(0-60)$ & $40(0-70)$ \\
$1 \mathrm{hr}$ & $30(20-35)$ & $30(20-50)$ & $30(15-40)$ & $20(10-30)$ \\
$2 \mathrm{hr}$ & $20(10-30)$ & $20(20-30)$ & $12.5(0-20)$ & $15(10-30)$ \\
$4 \mathrm{hr}$ & $5(0-10)$ & $20(0-20)$ & $0(0-20)$ & $0(0-40)$ \\
$6 \mathrm{hr}$ & $0(0-10)$ & $10(0-20)$ & $10(0-20)$ & $0(0-20)$ \\
$12 \mathrm{hr}$ & $20(0-30)$ & $10(10-30)$ & $17.5(0-20)$ & $2(0-30)$ \\
$24 \mathrm{hr}$ & $5(0-25)$ & $10(0-20)$ & $15(0-20)$ & $10(0-20)$ \\
$V A S-C$ & $30(20-40)$ & & & $45(15-70)$ \\
$4 \mathrm{hr}$ & $30(25-30)$ & $25(5-40)$ & $25(10-40)$ & $40(15-55)$ \\
$6 \mathrm{hr}$ & $45(25-70)$ & $20(10-30)$ & $30(15-25)$ & $35(20-60)$ \\
$12 \mathrm{hr}$ & $30(10-45)$ & $25(20-60)$ & $35(10-50)$ & $25(10-50)$ \\
$24 \mathrm{hr}$ & 37 & $20(10-40)$ & 50 & 37 \\
Shoulder pain (\% of patient) & $32(20-120)$ & 28 & $50(40-80)$ & $35(30-100)$ \\
Time to first analgesic (min) & $6(2.5-10)$ & $35(35-65)$ & $7(3-7)$ & $8(4-10)$ \\
Titrated morphine (mg) & $8(5-12)$ & $3(0-7)$ & $7(6-10)$ & $10(8-10)$ \\
Total morphine required (mg) & $4(1-4)$ & $5(3-8)$ & $4(2-6)$ & $4(2-4)$ \\
Propacetamol (g) & $0(0-50)$ & $4(2-4)$ & $0(0-50)$ & $0(0-50)$ \\
Ketoprofen (mg) & $0(0-100)$ & & \\
\hline
\end{tabular}

VAS- $\mathrm{R}=$ visual analogue scale at rest; VAS-C = visual analogue scale on coughing. Values are medians $(25$ th-75th) or percentage of patients (\%). No statistically significant differences between groups.

the VAS. If a patient reported pain (VAS $\geq 40$ ), the nursing staff administered boluses of $i v$ morphine $3 \mathrm{mg}$ every five minutes until the pain score was $<40 \mathrm{~mm}$ on the VAS. For the first $24 \mathrm{hr}$, the analgesia regimen, based on pain intensity, included the $i v$ administration of propacetamol, ketoprofen, and the sc administration of morphine. When the VAS was $\leq 40 \mathrm{~mm}$, propacetamol $\left(2 \mathrm{~g} \cdot 6 \mathrm{hr}^{-1}\right)$ was administered. When the VAS was $>40$ and $\leq 60 \mathrm{~mm}$, ketoprofen was given $(50 \mathrm{mg} \cdot 6$ $\left.\mathrm{hr}^{-1}\right)$. When the VAS was $>60 \mathrm{~mm}$, additional $s c$ morphine was given $\left(0.1 \mathrm{mg} \cdot \mathrm{kg}^{-1}\right)$. The degree of postoperative pain was assessed with the VAS at rest (VAS-R; supine, $20^{\circ}-30^{\circ}$ head up) on arrival at the PACU (time zero hour), 15, 30, 45 min and one-, two-, four-, six-,
12-, 24-hr intervals after surgery, and on coughing (VAS-C) at four-, six-, 12-, 24-hr intervals after surgery. Moreover, the incidence of shoulder pain, time to first analgesic request, analgesic requirements and existence of nausea or vomiting were assessed at the same time interval. Nausea and vomiting were treated as needed with $20 \mathrm{mg}$ iv metoclopramide. Sedation was also assessed using a four-point scale: $0=$ awake, $1=$ sleepy but awakened by oral command, 2 = sleepy but awakened by tactile stimulation, $3=$ not awakened.

\section{Statistical analysis}

We calculated that a power of 0.9 could be obtained, using a significance level of 0.05 and four groups of 13 
TABLE III Patients with sedation score $=1$ or more in the PACU or on the ward and patients experiencing nausea and/or vomiting.

\begin{tabular}{lllll}
\hline & $\begin{array}{l}\text { Group B } \\
(n=15)\end{array}$ & $\begin{array}{l}\text { Group } M \\
(n=16)\end{array}$ & $\begin{array}{l}\text { Group B+M } \\
(n=18)\end{array}$ & $\begin{array}{l}\text { Group S } \\
(n=16)\end{array}$ \\
\hline Sedation score $\geq 1$ & & & 78 & 75 \\
PACU (\% of patients) & 73 & 81 & 17 & 25 \\
Ward (\% of patients) & 40 & 37.5 & 17 & 27 \\
Nausea and/or vomiting (\% of patients) & 20 & 12.5 & 27 \\
\hline
\end{tabular}

Values are percentage of patients (\%). No statistically significant differences between groups. PACU = postanesthesia care unit.

patients, if a $25-\mathrm{mm}$ reduction in VAS ( $\mathrm{SD}=35 \mathrm{~mm}$ ) in the treatment group was to be regarded as a clinically significant result, based on the study by Narchi $e t$ al. ${ }^{9}$ To account for possible patient dropout we decided to include 18 patients per group.

As most analyzed quantitative variables could not meet the assumption of normality, with clearly skewed distributions, non parametric statistical methods were used for analysis. Such variables are presented as the median (25th-75th percentiles), while categorical variables are presented as frequencies (percentage of patients).

Quantitative variables were compared between groups at time zero and after two, six and $24 \mathrm{hr}$ by Kruskal-Wallis tests. Chi-square tests or Fisher's exact test when more appropriate were used to compare categorical variables across groups. In case of a significant difference when comparing the four groups, post-hoc two-by-two between-groups comparisons were performed with Bonferroni correction, using either Wilcoxon rank-sum tests for quantitative variables or Chi-square or Fisher's exact tests for categorical variables. Comparison of VAS-R and VAS-C was performed separately for each group, using Wilcoxon signed rank sum tests.

Statistical significance was inferred for $P \leq 0.05$, and all tests were two-sided. Data were analyzed using SAS v8.1 software (SAS Institute, Cary, NC, USA).

\section{Results}

Seven patients (three in group B, two in group M and two in group $S$ ) were excluded from the study: for three patients the laparoscopic procedure had to be converted to open surgery, for two patients the surgeon had to proceed to an early aspiration of the solution because of bleeding and two patients had a myomectomy.

\section{Demographic, surgical and anesthetic variables}

Demographic data (age, weight, height), ASA physical status, duration of surgery, total amount of propofol and alfentanil were similar in the four groups (Table I).

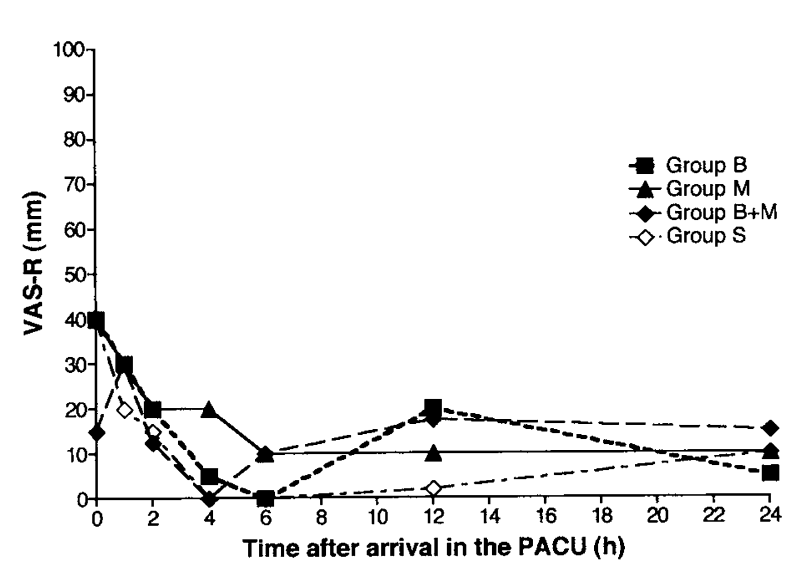

FIGURE 1 Postoperative visual analogue scale at rest (VAS-R). Values are medians. No statistical difference between groups.

\section{Postoperative period}

There were no significant differences in postoperative pain scores at rest and on coughing between the four groups (Table II, Figures 1 and 2). Time to first analgesic request or postoperative analgesic consumption were not different between groups (Table II). The rate of shoulder pain was similar in the four groups (Table II). Also, there were no significant differences in the incidence of side effects between patients. The four groups were comparable for sedation scores and for the number of patients experiencing nausea and vomiting (Table III).

\section{Discussion}

This study shows that the prophylactic ip injection of bupivacaine and/or morphine does not produce significant analgesia after laparoscopic gynecologic surgery compared to a multimodal analgesia regimen.

This study failed to demonstrate a superior analgesic efficacy of ip injection of local anesthetic compared to placebo. In their recent review, Moiniche et 


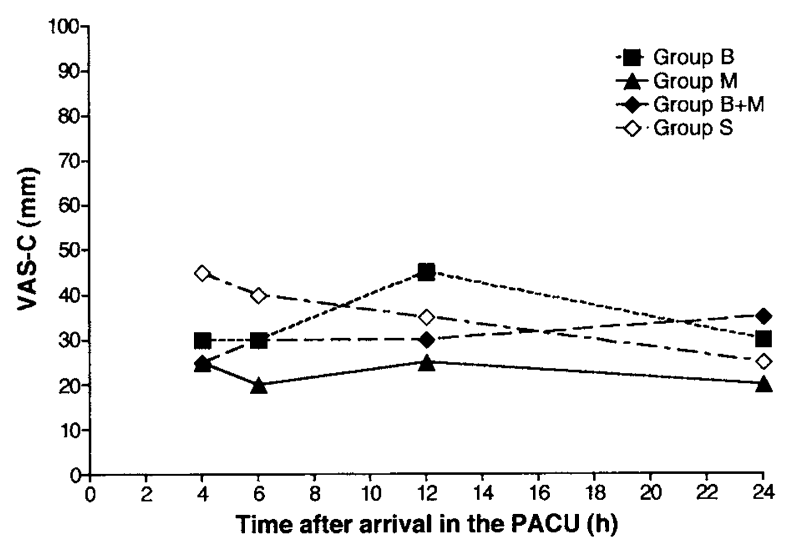

FIGURE 2 Postoperative visual analogue scale on coughing (VAS-C). Values are medians. No statistical difference between groups.

al., observed that studies of ip local anesthetics after laparoscopic surgery were poorly supportive of an effect on postoperative pain, especially after laparoscopic cholecystectomy. They concluded that the clinical benefit of this procedure, at least regarding pain scores, was questionable. In their review, a statistically significant weighted mean difference of $-13 \mathrm{~mm}$ VAS in favour of the treatment groups was observed after cholecystectomy. The difference was somewhat more pronounced in other procedures, including gynecological laparoscopy, with significant VAS reductions of up to $26 \mathrm{~mm} .{ }^{5}$ In our study, patients reported low postoperative pain scores in all groups, especially at rest. They also needed small doses of supplemental analgesics. This situation might be related to the short duration of surgery ${ }^{13}$ and/or to the fact that we used multimodal analgesia. ${ }^{14}$ We think that such low pain scores might have contributed to our inability to detect any analgesic effects of bupivacaine and/or morphine. It can also be argued that the failure to detect analgesic effects of ip bupivacaine is related to an insufficient amount of drug delivered to the surgical site. In fact, in 1991, Narchi and coworkers described the use of large volumes of dilute local anesthetic $(80 \mathrm{~mL}$ lidocaine $0.5 \%$ or $80 \mathrm{~mL}$ bupivacaine $0.125 \%$, both with epinephrine) administered before surgery into the peritoneal cavity for the treatment of pain after laparoscopy. ${ }^{9}$ They demonstrated significant reductions in mean pain scores in the local anesthetic groups from eight to $24 \mathrm{hr}$ after surgery compared to the control group. Thus, a possible explanation could be that, despite the administration of the same dose of bupivacaine (100 $\mathrm{mg}$ with epinephrine), the volume of solution was too small to reach the surgical site.

Despite the use of larger doses $(3 \mathrm{mg}$ morphine at the surgical site instead of $0.25 \mathrm{mg}$ in a previous study), ${ }^{11}$ we observed a similar negative result and the inefficacy of ip morphine. Schulte-Steinberg et al. have attributed the lack of efficacy of ip morphine in reducing postoperative pain after laparoscopic cholecystectomy to an insufficient dosage. ${ }^{11}$ Using a twelvefold higher dose of morphine, we observed the same result. To date, only the intra-articular injection of morphine showed a relatively constant efficacy. ${ }^{15}$ We speculate that, contrary to the knee joint which is a closed space and where doses of morphine between 0.5 and $5 \mathrm{mg}$ produce very high local concentrations, similar doses of morphine injected into the peritoneal cavity may be rapidly diluted and produce much lower local concentrations. An additional issue is that the knee joint model better reflects the inflammatory process that is thought to be of importance in sensitizing peripheral opioid receptors. ${ }^{16}$

A basic point of our study is that we investigated the value of prophylactic and not preemptive analgesia. In fact, contrary to preemptive analgesia which is defined as a treatment started before incision and covers both the period of surgery and initial postoperative period, ${ }^{17}$ we only evaluated the administration of treatment solutions at the beginning of the surgery.

A potential limitation of the current study is that we did not use patient-controlled analgesia morphine to quantify analgesic requirements. Nevertheless, we applied a standardized analgesic protocol adapted to regular and systematic evaluation of postoperative pain scores. Such a procedure has been reported to be comparable to patient-controlled analgesia for postoperative pain management. ${ }^{18}$

We conclude that in patients undergoing minor laparoscopic gynecologic surgery who receive a multimodal analgesic regimen, the prophylactic ip administration of $100 \mathrm{mg}$ bupivacaine with epinephrine and/or $3 \mathrm{mg}$ morphine does not provide significant analgesic benefit. However, since recent studies have reported an improvement of postoperative analgesia after laparoscopic cholecystectomy with the fractionated injection of local anesthetic (before and at the end of surgery), ${ }^{19,20}$ this practice should be evaluated in gynecologic surgery.

\section{References}

1 Schulze S, Thorup J. Pulmonary function, pain and fatigue after laparoscopic cholecystectomy. Eur J Surg 1993; 159: 361-4.

2 Soper NJ, Barteau JA, Clayman RV, Ashley SW, 
Dunnegan DL. Comparison of early postoperative results for laparoscopic versus standard open cholecystectomy. Surg Gynecol Obstet 1992; 174: 114-8.

3 Wiesel S, Grillas R. Patient-controlled analgesia after laparoscopic and open cholecystectomy. Can J Anaesth $1995 ; 42$ : 37-40.

4 Joris J, Cigarini I, Legrand M, et al. Metabolic and respiratory changes after cholecystectomy performed via laparotomy or laparoscopy. Br J Anaesth 1992; 69: 341-5.

5 Moiniche S, Jorgensen H, Wetterslev J, Dahl JB. Local anesthetic infiltration for postoperative pain relief after laparoscopy: a qualitative and quantitative systematic review of intraperitoneal, port-site infiltration and mesosalpinx block. Anesth Analg 2000; 90: 899-912.

6 Callesen T, Hjort D, Mogensen T, et al. Combined field block and i.p. instillation of ropivacaine for pain management after laparoscopic sterilization. Br J Anaesth 1999; 82: 586-90.

7 Goldstein A, Grimault P, Henique A, Keller M, Fortin $A$, Darai $E$. Preventing postoperative pain by local anesthetic instillation after laparoscopic gynecologic surgery: a placebo-controlled comparison of bupivacaine and ropivacaine. Anesth Analg 2000; 91: 403-7.

8 Helvacioglu A, Weis R. Operative laparoscopy and postoperative pain relief. Fertil Steril 1992; 57 : 548-52.

9 Narchi P, Benhamou D, Fernandez H. Intraperitoneal local anaesthetic for shoulder pain after day-case laparoscopy. Lancet 1991; 338: 1569-70.

10 Picard PR, Tramer MR, McQuay HJ, Moore RA. Analgesic efficacy of peripheral opioids (all except intra-articular): a qualitative systematic review of randomised controlled trials. Pain 1997; 72: 309-18.

11 Schulte-Steinberg $H$, Weninger E, Jokisch D, et al. Intraperitoneal versus interpleural morphine or bupivacaine for pain after laparoscopic cholecystectomy. Anesthesiology 1995; 82: 634-40.

12 Maitre PO, Vozeh S, Heykants J, Thomson DA, Stanski $D R$. Population pharmacokinetics of alfentanil: the average dose-plasma concentration relationship and interindividual variability in patients. Anesthesiology 1987; 66: 3-12.

13 Dabmani S, Dupont H, Mantz J, Desmonts JM, Keita $H$. Predictive factors of early morphine requirements in the post-anaesthesia care unit (PACU). Br J Anaesth 2001; 87: 385-9.

14 Kehlet $H$. Synergism between analgesics. Ann Med 1995; 27: 259-62.

15 Gupta A, Bodin L, Holmstrom B, Berggren L. A systematic review of the peripheral analgesic effects of intraarticular morphine. Anesth Analg 2001; 93: 761-70.

16 Nagasaka H, Awad H, Yaksh T. Peripheral and spinal actions of opioids in the blockade of the autonomic response evoked by compression of the inflamed knee joint. Anesthesiology 1996; 85: 808-16.

17 Kissin I. Preemptive analgesia. Anesthesiology 2000; 93: $1138-43$.

18 Choinière $M$, Rittenhouse BE, Perreault $S$, et al. Efficacy and costs of patient-controlled analgesia versus regularly administered intramuscular opioid therapy. Anesthesiology 1998; 89: 1377-88.

19 Pasqualucci A, De Angelis V, Contardo R, et al. Preemptive analgesia: intraperitoneal local anesthetic in laparoscopic cholecystectomy. Anesthesiology 1996; 85: 11-20.

20 Labaille T, Mazoit JX, Paqueron X, Franco D, Benhamou D. The clinical efficacy and pharmacokinetics of intraperitoneal ropivacaine for laparoscopic cholecystectomy. Anesth Analg 2002; 94: 100-5. 